The National

\section{Diabetes Prevention Programme}

Notwithstanding the human and financial implications of diabetes, we are concerned with the selective use of evidence to support the National Diabetes Prevention Programme. The editorial by Sood et al describes trials, which offered expensive, intensive interventions to participants selected on strict and extensive criteria with stringent methods to maintain participant engagement. ${ }^{1.2}$

Trials designed to emulate these randomised controlled trials have failed to reproduce the primary outcome of reduced diabetes incidence. ${ }^{3}$ Many lifestyle intervention trials in the UK and elsewhere have shown improvements in weight ${ }^{4}$ and blood glucose measurements, ${ }^{5}$ but have not reduced the incidence of diabetes. ${ }^{6}$

We hypothesise that policymakers have underestimated the complexity of sociocultural influences that predispose to diabetes and the barriers that need to be addressed to ensure success of "behaviour change' interventions.?

We encourage the National Diabetes Prevention Programme to heed the recommendations of experts ${ }^{8-10}$ and initiate a long-term primary prevention strategy applied at multiple levels including population and community components.

\section{Eleanor Barry,}

Academic GP Trainee, Barts and the London Medical School, London.

E-mail: eleanor.barryanhs.net

Trisha Greenhalgh,

Professor of Primary Care Health

Sciences, University of Oxford, Oxford.

\section{REFERENCES}

1. Sood HS, Maruthappu M, Valabhji J. The National Diabetes Prevention Programme: a pathway for prevention and wellbeing. Br J Gen Pract 2015: DOI: 10.3399/bjgp15X685537.

2. The Diabetes Prevention Program Research Group. Design and Methods for a clinical trial in the prevention of type 2 diabetes. Diabetes Care 1999; 22(4): 623-634.

3. Katula JA, Vitolins MZ, Morgan TM, et al. The
Healthy Living Partnerships to Prevent Diabetes study: 2-year outcomes of a randomized controlled trial. Am J Prev Med 2013; 44(4 Suppl 4): S324S332. DOI: 10.1016/j.amepre.2012.12.015

4. Oldroyd JC, Unwin NC, White M, et al. Randomised controlled trial evaluating lifestyle interventions in people with impaired glucose tolerance. Diabetes Res Clin Pract 2006; 72(2): 117-127.

5. Yates T, Davies M, Gorely T, et al. Effectiveness of a pragmatic education program designed to promote walking activity in individuals with impaired glucose tolerance: a randomized controlled trial. Diabetes Care 2009; 32(8): 1404-1410. DOI: 10.2337/dc090130.

6. Bhopal RS, Douglas A, Wallia S, et al. Effect of a lifestyle intervention on weight change in south Asian individuals in the UK at high risk of type 2 diabetes: a family-cluster randomised controlled trial. Lancet Diabetes Endocrinol 2014; 2(3): 218-227. DOI: 10.1016/S2213-8587(13)70204-3.

7. Greenhalgh T, Clinch M, Afsar N et al Sociocultural influences on the behaviour of South Asian women with diabetes in pregnancy: qualitative study using a multi-level theoretical approach. BMC Med 2015; 13: 120. DOI: 10.1186/s12916-015-0360-1.

8. Yudkin JS, Millet C. Diabetes prevention in England. Lancet Diabetes Endocrinol 2015; 3(7): 502. DOI: 10.1016/S2213-8587(15)00211-9.

9. Horton R. Mini essay: priorities for UK public health. Lancet 2014: http://uww.thelancet.com/healthchallenges-2040 (accessed 6 Aug 2015).

10.Wareham, NJ. Mind the gap: efficacy versus effectiveness of lifestyle interventions to prevent diabetes. Lancet Diabetes Endocrinol 2015; 3: 160-161

\section{Competing interests}

The authors are currently undertaking a quantitative and qualitative systematic review of the literature related to this subject.

DOI: 10.3399/bjgp15X686389

\section{Provision of medical student teaching in general practice}

May I humbly but strongly disagree with the comments made in a recent letter by Tim Lancaster in your Journal claiming that there is no link between exposure to general practice as an undergraduate student and future career choice to be a GP. ${ }^{1}$ Like much of medical education, there is of course no simple randomised controlled trial that links the complex sociological phenomenon of career choice and previous experience, but even a cursory glance at the latest career choices made by Foundation Doctors ${ }^{2}$ clearly illustrates the contrast of medical schools with high quantities of GP exposure (such as Keele or Hull York) and those with lower (such as Oxford or Edinburgh). Over the past 10 years we have asked our final year students at Newcastle University ( $n=2563$ ) before and after their GP rotation about their interest in general practice as a career. Consistently $35-40 \%$ report no interest before but an interest after their placement. Although not conclusive, surely this is a more persuasive argument than comparing current career intentions with those 40 years ago?

\section{Hugh Alberti,}

GP and Sub-Dean for Primary and Community Care, Newcastle University, Newcastle.

E-mail: hugh.albertiancl.ac.uk

\section{REFERENCES}

1. Lancaster T. Editor's choice [letter]. Br J Gen Pract 2015; DOI:10.3399/bjgp15X685165.

2. The UK Foundation Programme Office. F2 Career Destination Report 2014. http://www. foundationprogramme.nhs.uk/download. asp?file=F2 career destination report 2014 FINAL__App_A_updated.pdf (accessed 6 Aug 2015).

\title{
Mandatory reporting of FGM
}

The commendable editorial Mandatory reporting of female genital mutilation by healthcare professionals drew frontline health professionals' attention to proposed legal changes ${ }^{2}$ and their clinical implications. We agree with the authors' concerns regarding confidentiality. ${ }^{3}$

We wish to draw attention to the distinction between (a) mandatory reporting to the police of any girl or woman aged $<18$ years found to have undergone FGM, whenever it was performed; (b) the current 
mandatory submission of FGM statistics by acute trusts (the monthly submission of data by hospitals relating to every case of FGM identified, irrespective of age, to the Department of Health); and (c) the proposed Enhanced Dataset collection. This matters in an environment where doctors risk prosecution for not reporting appropriately.

GPs should be aware that the proposed Enhanced Dataset contains patientidentifiable information. While GMC guidance states that personal information can be disclosed if it is required by law', the benefits of mandatory data submission do not automatically outweigh the potential harm to the patient-doctor relationship and public trust. Our concern is that without assurance of confidentiality, FGM survivors may avoid seeking medical help in general practice, even for non-gynaecological conditions. Either a greater case needs to be made that this patient-identifiable data will prevent FGM or changes must be made to maintain confidentiality.

The classification of labial or clitoral piercings as Type 4 FGM for the purposes of the monthly statistics adds further confusion. ${ }^{2}$ This has the potential to undermine the validity and purpose of the data, notwithstanding the fact that many members of the general public and FGM survivors may find it objectionable that such piercings be considered equivalent to the crime of FGM.

Lastly, it was wrong for the authors to impugn the trainee in obstetrics and gynaecology recently exonerated of FGM when suturing after childbirth as "claiming to be ignorant of FGM' as if it were untrue, and without declaring the interest that one author had advised the prosecution. The jury's rapid decision to acquit after hearing all the evidence must be respected. Interestingly, in public discussion the breach of patient confidentiality at the heart of the story seems to have been lost.

While government involvement in FGM prevention is welcome, greater caution is required. Inadequately-considered interventions alongside intrusive surveillance within the doctor-patient relationship have the potential to cause great harm.

Joel Naftalin,

Trainee Representative to RCOG FGM Taskforce, Homerton University Hospital, London.

E-mail: joelnaftalinahotmail.com

Susan Bewley,

Professor of Complex Obstetrics, King's College London, London.

\section{REFERENCES}

1. Mathers N, Rymer J. Mandatory reporting of female genital mutilation by healthcare professionals. Br J Gen Pract 2015; D0I:10.3399/ bjgp15X685141

2. Health and Social Care Information Centre. Female Genital Mutilation (FGM) Enhanced Dataset: implementation quidance. http://www. hscic.gov.uk/media/16782/2026122014guidance/ pdf/2026122014guidance.pdf laccessed 6 Aug 2015)

3. BBC. Democracy Live. Home Affairs Committee. 6 May 2014. http://wnw.bbc.co.uk/democracylive/ house-of-commons-27294322 laccessed 6 Aug 2015)

4. General Medical Council. Confidentiality. http:// www.gmc-uk.org/static/documents/content/ Confidentiality___english.pdf laccessed 6 Aug 2015)

\section{Competing interests}

SB was a paid expert for the defence in the $2015 \mathrm{R} \mathrm{V}$ Dharmasena trial.

\section{DOI: 10.3399/bjgp15X686437}

\section{Prevalence of comorbid depression and obesity in general practice}

I read with great interest the article by Carey et al. ${ }^{1}$ As a co-tutor of the master thesis related to a similar topic, ${ }^{2}$ I would like to respond even at this late stage.

A cross-sectional study was carried out among 56 primary care patients, mean age 48.71 years $\pm 10.78,24$ overweight women (BMI $25-<30 \mathrm{~kg} / \mathrm{m}^{2}$ ) and 32 obese women (BMI $\leq 30 \mathrm{~kg} / \mathrm{m}^{2}$ ), in the city of Niš (south east part of Serbia). The Patient Health Questionnaire (PHQ-9) was used to assess depression. ${ }^{3}$ A score of $\geq 10$ on a 27 -point scale was used to define clinically-relevant depressive symptoms. Body weight and height were measured to the nearest $0.1 \mathrm{~kg}$ and $0.1 \mathrm{~cm}$, respectively, by using standardised equipment and body mass index (BMI) was calculated as weight $(\mathrm{kg})$ divided by the square of height $\left(\mathrm{m}^{2}\right)$.

The prevalence of depression in our study was similar among overweight and obese participants (48.4\% and $51.6 \%$ respectively) and significantly higher compared to the prevalence of depression in the general population (between 16\% and 34\%) However, for only one-sixth (between 12\% and $16 \%$ ) of the participants, a diagnosis of depression has been confirmed. The most common symptoms of depression were overeating $(74.6 \%)$ and loss of energy (69.3\%). The average PHQ-9 score was $9.967 \pm 4.79$, represented mild form of depression. Univariate logistic regression analysis identified the duration of obesity as a risk factor for depression and every year duration of obesity increased the risk of depression for $7.7 \%$.

We have to bear in mind the current social circumstances that have a strong influence on the prevalence of mental disease in the countries in transition. For example, depression is the leading cause of nonfatal disease burden in Serbia. In addition, mental illness is associated with stigma in these countries, so the symptoms of depression may often be overlooked and go untreated in the GP's practice.

To conclude, PHQ-9 is a really useful screening tool for depression for all obese patients attending ambulatory care. Further studies should focus on various socioeconomic and cultural environments and barriers.

Majo Nikolic,

Associate Professor, Faculty of Medicine University of Niš, Niš, Serbia.

E-mail: maniajunis.ni.ac.rs

\section{REFERENCES}

1. Carey M, Small H, Yoong SL, et al. Prevalence of comorbid depression and obesity in general practice: a cross-sectional survey. Br J Gen Pract 2014; DOI: 10.3399/bjgp14X677482.

2. Ulic $V$. Prevalence of depression and anxiety among obese individuals. MSc Thesis. [in Serbian]. Niš: Faculty of Medicine University of Niš, 2014.

3. International Physical Activity Questionnaire. IPAQ research committee, 2005. http://www. phqscreeners.com/overview.aspx?Screener $=02$ PHQ-9 (accessed 6 Aug 2015)

DOI: 10.3399/bjgp15X686449

\section{Increasing collaboration between GPs and dental practitioners}

GPs, dentists, nurses, care workers, pharmacists, and many others ${ }^{1}$ are at the forefront of primary care. Despite differences in working conditions and 